\title{
Primary spontaneous complete posterior colporrhexis during labour: a rare case report
}

\author{
Shashi Lata Kabra, Ritu Goyal, Reema Jain*, VK Kadam
}

Department of Obstetrics and Gynaecology, DDU Hospital, Delhi, India

Received: 12 May 2016

Accepted: 04 June 2016

\section{*Correspondence:}

Dr. Reema Jain,

E-mail: reemaforfb@gmail.com

Copyright: () the author(s), publisher and licensee Medip Academy. This is an open-access article distributed under the terms of the Creative Commons Attribution Non-Commercial License, which permits unrestricted non-commercial use, distribution, and reproduction in any medium, provided the original work is properly cited.

\begin{abstract}
Uterus rupture in the course of labour is a well-documented fact, but the majority of the cases occur in scarred uterus. The scarred uterus can be secondary to previous surgeries like caesarean section, myomectomy, perforations etc. Nevertheless, primary spontaneous colporrhexis that occurs in a presumable normal tissue of the uterus instead of the previous scar site is a rare condition. Here we report the case of a 26 year old woman who had a posterior colporrhexis during her trial for normal delivery after previous caesarean section with intact scar site. Such cases though very rare, but set up an example of the need to remain extra vigilant while monitoring every women in labour irrespective of previous scarred uterus or not.
\end{abstract}

Keywords: Colporrhexis, Caesarean, Rupture

\section{INTRODUCTION}

Colporrhexis is defined as rupture of vaginal vault or upper one third of vaginal wall. ${ }^{1}$ It can occur both in pregnant as well as non-pregnant uterus. Coitus and force by foreign body in already weakened vagina because of post-menopausal atrophy or previous surgery are the causes in non-pregnant uterus. Marked obliquity of uterine axis, uterine deflexion, weakened vaginal wall and multiparity are important causes in pregnant uterus. Colporrhexis is subdivided into primary or secondary, spontaneous or traumatic, complete or incomplete. Incomplete colporrhexis includes rupture of the vaginal epithelium and the muscular is, whereas complete involves the overlying peritoneum as well. Clinical manifestations are similar to the rupture uterus, not severe though, sudden cessation of labour pains, followed by continuous pain, vaginal bleeding or sign symptom of shock may be there. ${ }^{2}$

\section{CASE REPORT}

Our patient was a 26 year old woman, gravida two and para one, admitted in the labour room with spontaneous labour at term. She revealed the obstetrics history of previous one lower segment caesarean section (LSCS) done for cord around neck at a tertiary hospital 3 years back. No history of any antepartum, intra partum or postpartum complication given by her. She did not receive any ante natal check-up in this pregnancy.

On admissions, her vitals were stable with uterus corresponding to 36 weeks, having adequate contractions and foetal heart sounds were regular in rate and rhythm. On per vaginal examination she was $6 \mathrm{~cm}$ dilated, $70 \%$ effaced with vertex at 0 station and clear liquor draining. After taking proper consent, trial for vaginal delivery was done in view of favourable bishop's Score. 


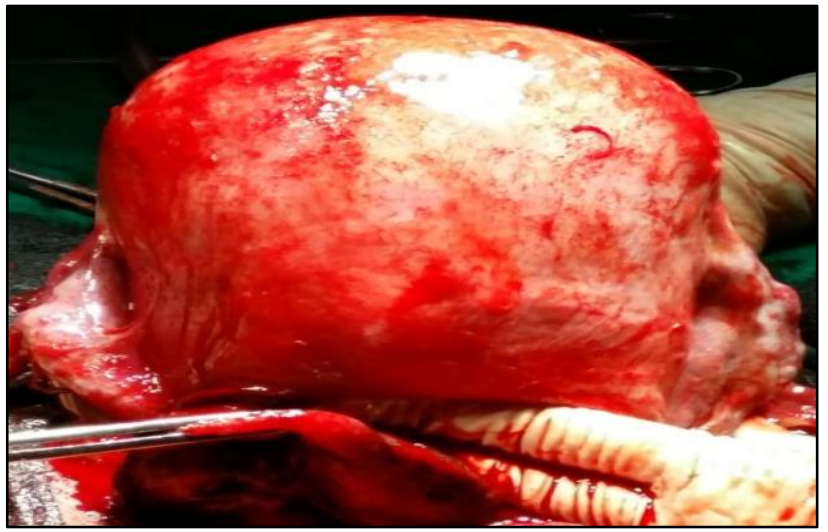

Figure 1: Posterior vaginal wall rupture exposing the underlying.

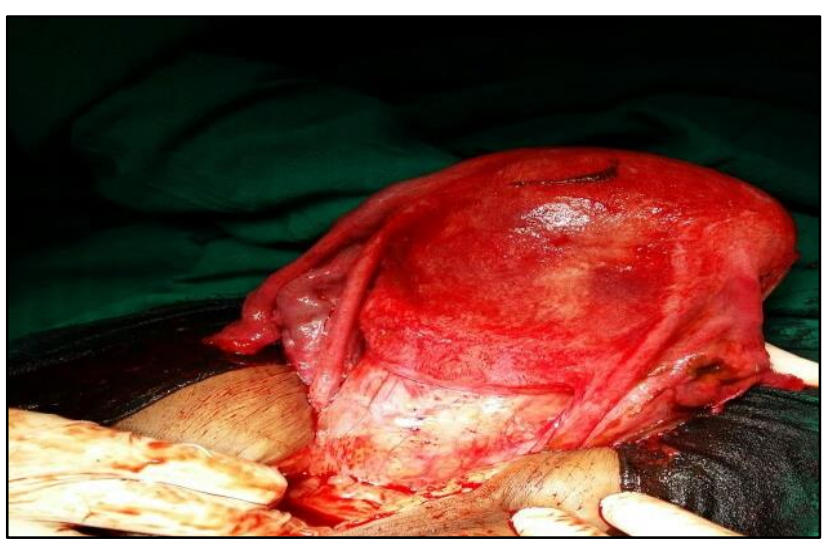

Figure 2: Intact anterior uterine wall and previous scar site.

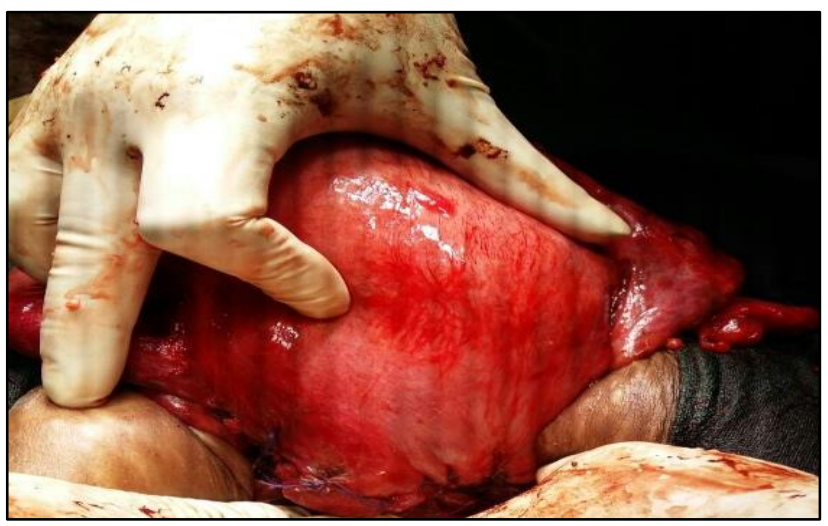

Figure 3: Posterior colporrhexis after repair.

The labour progressed smoothly. Augmentation was not done since she had adequate contractions. After around 3 hours, she complained of sudden onset of acute pain, with monitor showing sudden fall in blood pressure and tachycardia. Abdominally superficial foetal parts were palpable with loss of uterine contour and absent foetal heart sound. Per vaginally she was fully dilated fully effaced, vertex at plus one station and considerable vaginal bleeding. She was immediately prepared and shifted to operation theatre for laparotomy in view of suspected rupture. Intraoperative, foetus along with placenta was found lying in the abdominal cavity with haemoperitoneum of around 1.5 litres. Dead foetus weighing $2.7 \mathrm{~kg}$, along with placenta was extracted. Exploration was then done to find the site of rupture. Surprisingly the site of rupture was neither the previous scar site nor the anterior uterine wall rather the site of rupture was posterior vaginal wall (cul-de-sac). Around 8 $\mathrm{cm}$ laceration of the posterior vaginal wall was seen extending to the bilateral uterosacral ligaments, with intact dilated cervix visible through it. The margins of the tear were identified and primary repair done by applying multiple stay sutures along both the margins of the tear and then ultimately opposing them in an effort to save the uterus since the patient wanted more children and had refused ligation. Bilaterally ureters were traced and were found intact. Post operatively patient did well, had stable vitals. At the time of discharge patient was well counselled and educated about the need for regular ante natal check-ups and need for elective lscs in her next pregnancy.

\section{DISCUSSION}

Although the clinical picture in this patient was that of a rupture of the uterus, during surgery it turned out that the uterus was intact and spontaneous primary posterior colporrhexis had taken place. In the case presented above, no cause could be identified. Review of literature shows only few cases of primary spontaneous colporrhexis reported so far. ${ }^{3,4}$ Moreover, with the exception of lscs scar (which was not involved in rupture), the patient had none of the risk factors associated with the rupture, such as induction augmentation obstructed labour or any other risk factor.

Four methods of treatment have been described in such cases. The first is to allow healing by secondary intention, which is now obsolete. The second involves two-layer closure, and the third is to close in one layer. The fourth option is to perform a hysterectomy when the exposure is poor, and when there is severe blood loss. In our case repair was tried, in favor of patient's interest, and was successful, thus conserving her future fertility, which indeed will require proper management again.

\section{CONCLUSION}

Though the type of the case described above is very rare, but by reviewing this case, we should keep in mind that concealed rupture of vagina and uterus do occur and each and every women in labour (whether having previous uterine scar or not) should be monitored carefully, so as to diagnose such mishap early to avoid maternal and foetal mortality and morbidity.

Funding: No funding sources Conflict of interest: None declared

Ethical approval: Not required 


\section{REFERENCES}

1. Greenhill JP. Principles and practice of obstetrics $10^{\text {th }}$ edition. Philadelphia and London: WB Saundus Co; 1951:713.

2. Guise JM, McDonagh MS, Osterweil P, Nygren P, Chan BKS, Helfand M. Systematic review of the incidence and consequences of uterine rupture in women with previous caesarean section. British Medical Journal. 2004;329(7456):19-25.

3. Brews AA. Manual of obstetrics (Eden and Holland), $9^{\text {th }}$ edition. London: J. and A. Churchill; 1948:484.

4. Young B, Takoudes T, Lim KH, Rana S. Rupture of the posterior cul-de-sac during spontaneous labor. Obstetrics and Gynecology. 2010;115(part 2:2):4147.

Cite this article as: Kabra SL, Goyal R, Jain R, Kadam VK. Primary spontaneous complete posterior colporrhexis during labour: a rare case report. Int J Reprod Contracept Obstet Gynecol 2016;5:2463-5. 